\title{
Angiographic Findings of the Multicenter Randomized Study With the Sirolimus-Eluting Bx Velocity Balloon-Expandable Stent (RAVEL) : Sirolimus-Eluting Stents Inhibit Restenosis Irrespective of the Vessel Size
}

E. Regar, P.W. Serruys, C. Bode, C. Holubarsch, J.L. Guermonprez, W. Wijns, A. Bartorelli, C. Constantini, M. Degertekin, K. Tanabe, C. Disco, E. Wuelfert and M.C. Morice

\author{
Circulation. 2002;106:1949-1956 \\ doi: 10.1161/01.CIR.0000034045.36219.12
}

Circulation is published by the American Heart Association, 7272 Greenville Avenue, Dallas, TX 75231

Copyright (C) 2002 American Heart Association, Inc. All rights reserved.

Print ISSN: 0009-7322. Online ISSN: 1524-4539

The online version of this article, along with updated information and services, is located on the World Wide Web at:

http://circ.ahajournals.org/content/106/15/1949

\footnotetext{
Permissions: Requests for permissions to reproduce figures, tables, or portions of articles originally published in Circulation can be obtained via RightsLink, a service of the Copyright Clearance Center, not the Editorial Office. Once the online version of the published article for which permission is being requested is located, click Request Permissions in the middle column of the Web page under Services. Further information about this process is available in the Permissions and Rights Question and Answer document.
}

Reprints: Information about reprints can be found online at:

http://www.lww.com/reprints

Subscriptions: Information about subscribing to Circulation is online at:

http://circ.ahajournals.org//subscriptions/ 


\title{
Angiographic Findings of the Multicenter Randomized Study With the Sirolimus-Eluting Bx Velocity Balloon-Expandable Stent (RAVEL)
}

\section{Sirolimus-Eluting Stents Inhibit Restenosis Irrespective of the Vessel Size}

\author{
E. Regar, MD; P.W. Serruys, MD, PhD; C. Bode, MD; C. Holubarsch, MD; J.L. Guermonprez, MD; \\ W. Wijns, MD; A. Bartorelli, MD; C. Constantini, MD; M. Degertekin, MD; K. Tanabe, MD; \\ C. Disco, MSc; E. Wuelfert, BPharm, MSc, M.C. Morice, MD; on Behalf of the RAVEL Study Group
}

Background-Restenosis remains the major limitation of coronary catheter-based intervention. In small vessels, the amount of neointimal tissue is disproportionately greater than the vessel caliber, resulting in higher restenosis rates. In the Randomized Study With the Sirolimus-Eluting Bx Velocity Balloon-Expandable Stent (RAVEL) trial, $\approx 40 \%$ of the vessels were small $(<2.5 \mathrm{~mm})$. The present study evaluates the relationship between angiographic outcome and vessel diameter for sirolimus-eluting stents.

Methods and Results-Patients were randomized to receive either an 18-mm bare metal Bx VELOCITY (BS group, $\mathrm{n}=118$ ), or a sirolimus-eluting Bx VELOCITY stent (SES group, $\mathrm{n}=120$ ). Subgroups were stratified into terciles according to their reference diameter (RD; stratum I, RD $<2.36 \mathrm{~mm}$; stratum II, RD $2.36 \mathrm{~mm}$ to $2.84 \mathrm{~mm}$; stratum III, $\mathrm{RD}>2.84 \mathrm{~mm}$ ). At 6-month follow-up, the restenosis rate in the SES group was $0 \%$ in all strata (versus 35\%, 26\%, and $20 \%$, respectively, in the BS group). In-stent late loss was $0.01 \pm 0.25$ versus $0.80 \pm 0.43 \mathrm{~mm}$ in stratum I, $0.01 \pm 0.38$ versus $0.88 \pm 0.57 \mathrm{~mm}$ in stratum II, and $-0.06 \pm 0.35$ versus $0.74 \pm 0.57 \mathrm{~mm}$ in stratum III (SES versus BS). In SES, the minimal lumen diameter (MLD) remained unchanged ( $\Delta-0.72$ to $0.72 \mathrm{~mm}$ ) in $97 \%$ of the lesions and increased (=late gain, $\Delta \mathrm{MLD}<-0.72 \mathrm{~mm}$ ) in $3 \%$ of the lesions. Multivariate predictors for late loss were treatment allocation $(P<0.001)$ and postprocedural MLD $(P=0.008)$.

Conclusions-Sirolimus-eluting stents prevent neointimal proliferation and late lumen loss irrespective of the vessel diameter. The classic inverse relationship between vessel diameter and restenosis rate was seen in the bare stent group but not in the sirolimus-eluting stent group. (Circulation. 2002;106:1949-1956.)

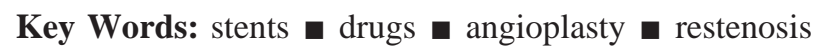

$\mathrm{R}$ estenosis remains the major limitation of coronary catheter-based intervention. ${ }^{1}$ In stented vessels, the major contributor to restenosis is neointimal proliferation, which is a ubiquitous, local, vascular reaction to catheter-induced vessel injury. ${ }^{2}$ Vessel diameter is an established predictor of angiographic outcome after catheter-based intervention, with a higher restenosis rate in smaller vessels. ${ }^{3}$ This is because of the disproportionately greater amount of neointimal tissue relative to the vessel caliber. ${ }^{4}$ Although coronary stents provide major benefits versus simple balloon angioplasty by inhibiting acute vessel closure, early vessel recoil, and late vessel constriction, they stimulate neointimal proliferation. Therefore, restenosis rates in small vessels may be similarly high with these 2 treatment modalities. ${ }^{5,6}$ Inhibition of neo- intimal proliferation by local pharmacological interventions is a promising concept. Sirolimus (rapamycin) is an immunosuppressive drug approved for the prevention of renal transplant rejection. It also has potent antiproliferative and antimigratory effects on vascular smooth muscle cells. ${ }^{7} \mathrm{Re}$ cent clinical experience with sirolimus-eluting coronary stents has shown excellent results, with $0 \%$ restenosis at 4-month, ${ }^{8}$ 6-month, ${ }^{9}$ and 12-month follow-up. ${ }^{10}$ At the time of these pilot studies, sirolimus-eluting stents were only available in a $3.0-\mathrm{mm}$ or $3.5-\mathrm{mm}$ diameter, limiting treatment to relatively large vessels. In the Randomized Study With the Sirolimus-Eluting Bx Velocity Balloon-Expandable Stent (RAVEL) trial, a smaller sirolimus-eluting stent with a diameter of $2.5 \mathrm{~mm}$ was available, and it allowed smaller

Received April 25, 2002; revision received July 18, 2002; accepted July 29, 2002.

From Thoraxcenter, Rotterdam, the Netherlands (E.R., P.W.S., M.D., K.T.); Medizinische Universitätsklinik, Freiburg, Germany (C.B., C.H.); Hôpital Broussais, Paris, France (J.L.G.); Onze Lieve Vrouw Klinik, Aalst, Belgium (W.W.); Centro Cardiologico, Milano, Italy (A.B.); Clinico Cardiologico, Curitibana, Parana, Brasil (C.C.); Cardialysis BV, Rotterdam, the Netherlands (C.D.); Cordis Corporation, Waterloo, Belgium (E.W.); and L'Institut Cardiovasculaire Paris-Sud, Massy, France (M.C.M.).

Correspondence to Prof P.W. Serruys MD, PhD, Thoraxcentre, Bd. 408, University Hospital Dijkzigt, Dr. Molewaterplein 40, 3015 GD Rotterdam, The Netherlands. E-mail Serruys@ card.azr.nl

(C) 2002 American Heart Association, Inc.

Circulation is available at http://www.circulationaha.org 

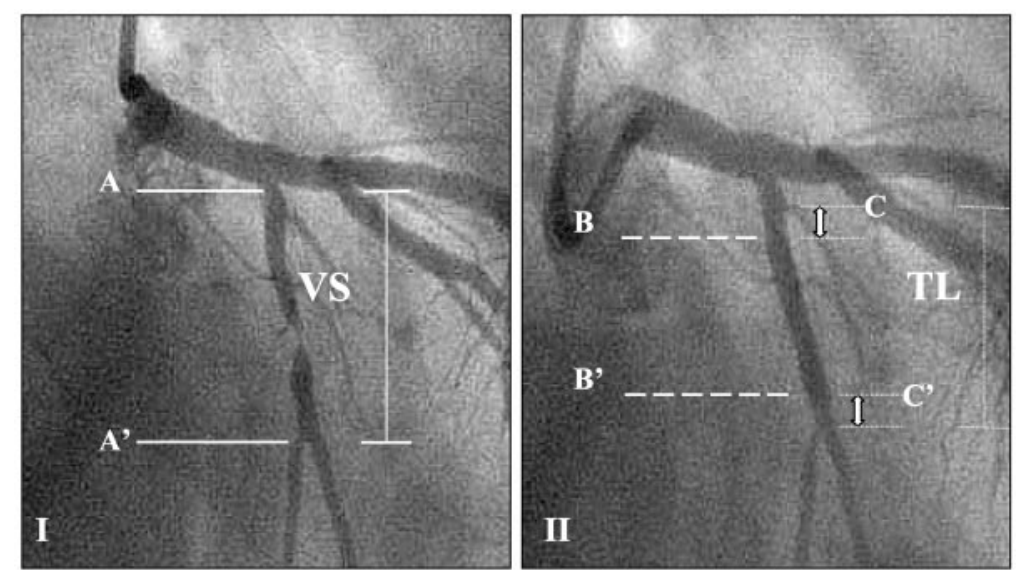

Figure 1. I, Vessel segment (VS) was defined as the segment bounded by side branches proximal $(A)$ and distal $\left(A^{\prime}\right)$ to the stent segment. II, Target lesion (TL) encompassed the stent segment and edge segments. The length of the vessel covered by stent struts defined the stent segment (from B to $\left.B^{\prime}\right)$. The edge segments encompassed the vessel $5 \mathrm{~mm}$ proximal $(C)$ and distal $\left(\mathrm{C}^{\prime}\right)$ to the stent. vessels to be stented. This small sirolimus-eluting stent was used in $18 \%$ of patients. ${ }^{11}$ The present study investigated the relationship between angiographic outcome and vessel diameter for sirolimus-eluting stents compared with bare metal stents.

\section{Methods}

\section{Patients and Stent Implantation}

The patient population and stent implantation technique have been described in detail elsewhere. ${ }^{11}$ The 238 patients enrolled in the RAVEL trial had a single de novo lesion of a native coronary artery.

Patients were randomized (double-blind) for implantation of either an 18-mm uncoated bare metal Bx VELOCITY stent (BS), or a sirolimus-eluting Bx VELOCITY balloon-expandable stent (Cordis Corp, Johnson \& Johnson) (SES). All drug-eluting Bx VELOCITY stents contained $140 \mu \mathrm{g}$ sirolimus $/ \mathrm{cm}^{2}( \pm 10 \%)$. Total sirolimus content was $153 \mu \mathrm{g}( \pm 10 \%)$ on the 6-cell stent $(2.5$ and $3.0 \mathrm{~mm}$ in diameter) and $180 \mu \mathrm{g}( \pm 10 \%)$ on the 7 -cell stent $(3.5 \mathrm{~mm}$ in diameter). This difference in content was due to the differences in the surface area of the two stents. Stent implantation was performed in the conventional manner after predilation. Postdilatation was performed as necessary to achieve a residual stenosis below $20 \%$ with TIMI grade III flow. Patients received aspirin (at least $100 \mathrm{mg}$ ) indefinitely with either clopidogrel (75 mg daily) or ticlopidine (250 $\mathrm{mg}$, twice daily) for 8 weeks.

\section{Quantitative Coronary Angiographic Analysis}

Coronary angiograms were obtained in multiple views after intracoronary injection of nitrates. Quantitative analyses by edge-detection techniques were performed by an independent core laboratory (Cardialysis BV) blinded to treatment allocation. Reference diameter (RD), minimal luminal diameter (MLD), and degree of stenosis (as percentage of diameter) were measured before dilatation, at the end of the procedure, and at a 6-month follow-up. Restenosis was defined as $>50 \%$ diameter stenosis at follow-up. Late loss was defined as MLD after the procedure minus MLD at follow-up.

The target lesion was defined as the stent segment plus $5 \mathrm{~mm}$ proximal and $5 \mathrm{~mm}$ distal to the edge of the stent. The vessel segment was defined as the segment bounded by side branches proximal and distal to the stent segment (Figure 1).

The accuracy of the method has been reported in detail. ${ }^{12}$ Given the accuracy of quantitative coronary angiography for MLD measurements, we used 2 standard deviations ${ }^{12}$ as the cut-off point for the classification of late loss indicating whether MLD was unchanged (no loss, $\triangle \mathrm{MLD}-0.72$ to $0.72 \mathrm{~mm}$ ), reduced (late loss, $\Delta \mathrm{MLD}>0.72 \mathrm{~mm}$ ), or larger (late gain, $\triangle \mathrm{MLD}<-0.72 \mathrm{~mm}$, "negative late loss") at follow-up. ${ }^{13}$

\section{Subgroup Definition}

Both groups were stratified according to their vessel diameter. Vessel diameter was defined as the baseline RD in the vessel segment analysis before intervention. The terciles for the RD were calculated and used as cut-off points for subgroup definition.

\section{Sample Size Estimation and Statistical Analysis Based on Late Loss}

A sample size of 95 in each group had $87 \%$ power to detect a difference in means of $0.25 \mathrm{~mm}$ (the difference between a bare stent late loss mean, $\mu_{\mathrm{B}}$, of $0.80 \mathrm{~mm}$ and a sirolimus stent late loss mean, $\mu_{\mathrm{S}}$, of $0.55 \mathrm{~mm}$ ), assuming that the common standard deviation is 0.55 using a 2 -group $t$ test with a 0.051 -sided significance level. The sample size was increased to 110 in each group to account for noncompliance to 6-month angiographic follow-up.

Data are presented as mean \pm SD or proportions. For comparison of continuous data, a 2-tailed Student's $t$ test was performed. A value of $P<0.05$ was considered significant. To identify the factors that might be related to late lumen loss, linear regression analyses were performed. Predictors were chosen by stepwise linear regression using an entry criterion of 0.20 and a stay criterion of 0.05 .

\section{Results}

The 238 patients were randomly assigned (SES, $\mathrm{n}=120$; BS, $\mathrm{n}=118$ ). There were no significant differences with regard to procedural success $(96.6 \%$ versus $93.1 \%)$, stents per patient (1.0 \pm 0.3 versus $1.1 \pm 0.3)$, and nominal stent diameter $(3.06 \pm 0.34 \mathrm{~mm}$ versus $3.10 \pm 29 \mathrm{~mm}$; SES versus BS, respectively).

Before the procedure, RD $(2.60 \pm 0.54 \mathrm{~mm}$ versus $2.64 \pm 0.52 \mathrm{~mm})$ and MLD $(0.94 \pm 0.31 \mathrm{~mm}$ versus $0.95 \pm 0.35 \mathrm{~mm}$ ) were similar in both groups. After the procedure, there were also no meaningful differences (postprocedural $\mathrm{RD}, 2.62 \pm 0.44 \mathrm{~mm}$ versus $2.68 \pm 0.45 \mathrm{~mm}$; postprocedural MLD, 2.43 $\pm 0.41 \mathrm{~mm}$ versus $2.41 \pm 0.40 \mathrm{~mm}$; SES versus BS, respectively). At follow-up, the SES group showed a larger MLD $(2.42 \pm 0.49 \mathrm{~mm}$ versus $1.64 \pm 0.59 \mathrm{~mm}, P<0.001)$ and lower late lumen loss $(-0.01 \pm 0.33 \mathrm{~mm}$ versus $0.80 \pm 0.53 \mathrm{~mm}$, $P<0.001)$. Binary restenosis was $0.0 \%$ in the SES group and $26.6 \%$ in the BS group $(P<0.001)$.

Figure 2 illustrates the relation between postprocedural MLD and MLD at follow-up. In the SES group, the MLD (Figure 2A) remained basically unchanged; late loss was seen in 1 lesion and late gain was seen in 4 lesions (3\%). In contrast, lumen reduction over time was seen in approximately half of the BS patients $(n=55,47 \%)$, and no late gain 
A
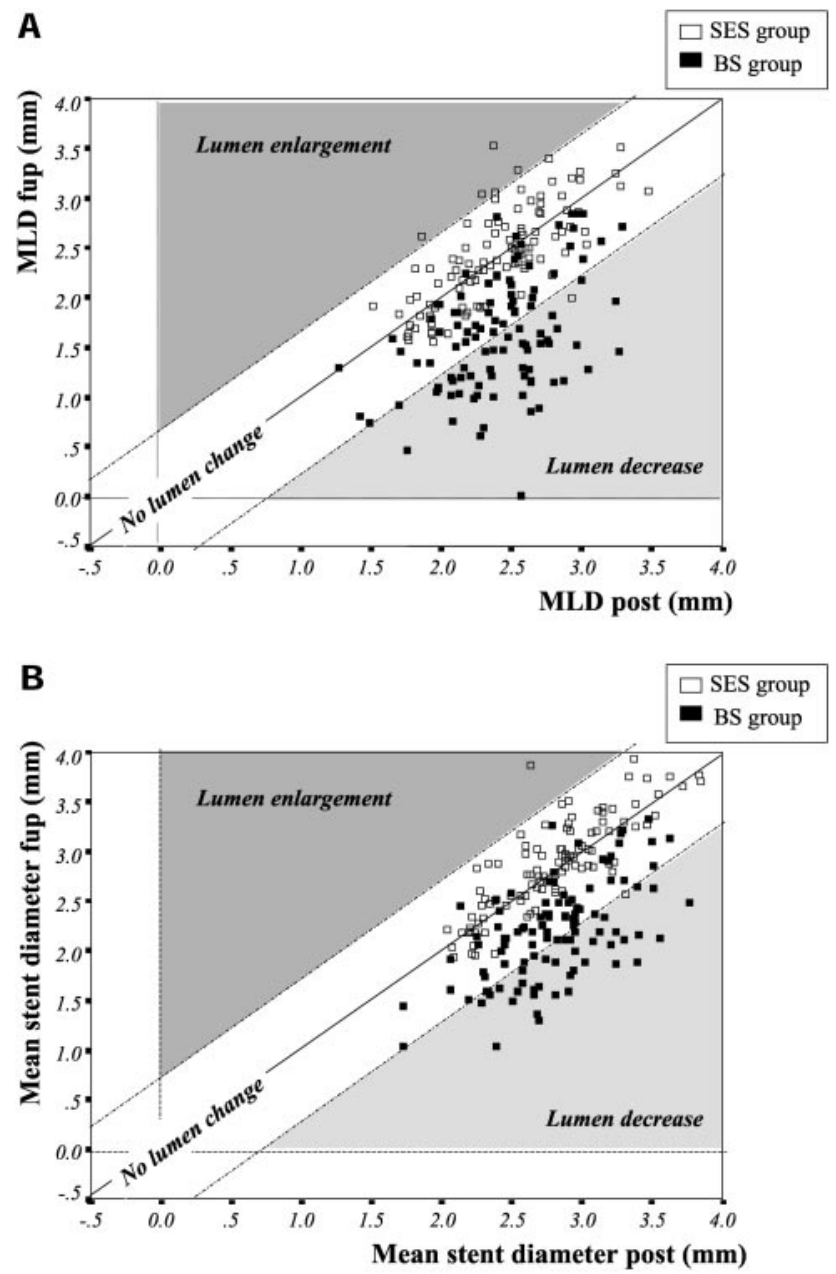

Figure 2. Relationship between measurements after implantation and at 6-month follow-up for the SES group and the BS group: MLD (A), mean diameter over the entire length of the stent $(B)$. Dashed lines indicate the range of $\pm 0.72 \mathrm{~mm}$ change in diameter.

was seen. A similar pattern was found for the mean diameter over the entire length of the stent (Figure 2B).

\section{Stratification}

Subgroups were stratified according to their RD (Figure 3). There were no significant differences in baseline patient and lesion characteristics in the SES and BS subgroups. There were also no significant differences in procedural parameters (Table 1).

Analysis of the strata revealed a higher proportion of diabetic patients in small and intermediate vessels. The stent implantation procedure showed a decreasing balloon to artery ratio (stratum I versus stratum III: $P<0.001$ in both, BS and SES group) and increasing inflation pressure from stratum I to stratum III (stratum I versus stratum III: $P<0.01$ SES group; $P=0.22 \mathrm{BS}$ group).

Table 2 summarizes the key angiographic data. Vessel segment analysis showed similar preprocedural and postprocedural MLD in both treatment groups throughout corresponding strata.

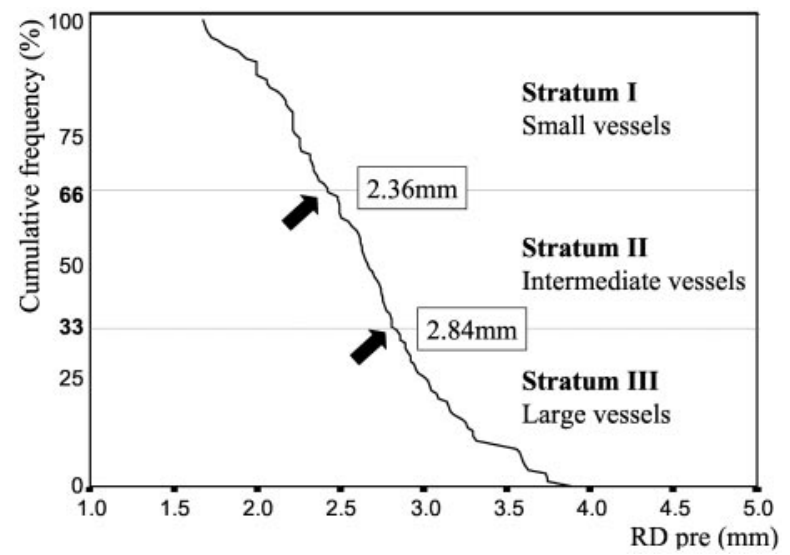

Figure 3. Subgroup stratification: cumulative frequency distribution curve of the preinterventional reference diameter. Arrows indicate cut-off values at the 33rd and the 66th percentile.

\section{Restenosis, Late Lumen Loss, and Vessel Size}

At follow-up, the MLD was consistently larger in the SES groups. In all strata, the restenosis rate was $0 \%$ in the SES groups, with extremely low and consistently uniform late loss. In the BS strata, the classic inverse relationship between restenosis rate and vessel diameter was seen. Restenosis rate virtually doubled with decreasing vessel size from $20 \%$ in large vessels (stratum III) to $35 \%$ in small vessels (stratum I). The amount of late loss, however, was similar in the 3 groups $(0.80 \mathrm{~mm}$ in stratum I, $0.88 \mathrm{~mm}$ in stratum II, and $0.74 \mathrm{~mm}$ in stratum III). Therefore, the observed increase in restenosis rate in smaller vessels in this series is driven largely by the relative amount of obstruction as a function of vessel diameter rather than being due to an absolute increase in neointimal hyperplasia in smaller vessels.

\section{Subsegment Analysis}

Vessel Segment Analysis

Vessel segment analysis revealed minimal late gain in both the MLD and RD over time in SES subgroups but not in BS groups (Table 2).

\section{Target Lesion Analysis (Including Stent Segment and the Proximal and Distal Edges)}

The SES subgroups showed minimal late loss at the stent segment $(0.01 \pm 0.25 \mathrm{~mm}, 0.01 \pm 0.38 \mathrm{~mm}$, and $-0.06 \pm 0.35 \mathrm{~mm}$ in strata I, II, and III, respectively) and proximal edges $(0.04 \pm 0.34 \mathrm{~mm}$, $0.08 \pm 0.42 \mathrm{~mm}$, and $0.03 \pm 0.43 \mathrm{~mm}$ in strata I, II, and III, respectively), whereas the distal SES edges had minimal late gain $(-0.05 \pm 0.29 \mathrm{~mm},-0.14 \pm 0.31 \mathrm{~mm}$, and $-0.09 \pm 0.31 \mathrm{~mm}$ in strata I, II, and III, respectively). In contrast, the BS subgroups showed pronounced late loss in the stent segment and moderate late loss at the proximal and distal edges.

\section{Multivariate Analysis}

Univariate predictors for late loss included treatment allocation and postprocedural MLD (Table 3). Multivariate predictors for late loss were treatment allocation $(P<0.001)$ and the MLD after the procedure $(P=0.008)$ (Table 4$)$. 
TABLE 1. Baseline Characteristics for Sirolimus-Eluting and Bare Stents, Stratified by Vessel Size

\begin{tabular}{|c|c|c|c|c|}
\hline Stratum/Parameter & SES & BS & Difference $(95 \% \mathrm{Cl})$ & $P$ \\
\hline \multicolumn{5}{|l|}{ I } \\
\hline $\mathrm{n}$ & 42 & 37 & $\ldots$ & $\cdots$ \\
\hline Age, y & $62 \pm 12$ & $62 \pm 10$ & $-0.4(-5.0,4.3)$ & $\cdots$ \\
\hline Male sex & 73.8 & 75.7 & $-1.9(-21.0,17.3)$ & $\ldots$ \\
\hline Diabetes mellitus & 19.0 & 27.0 & $-8.0(-26.6,10.6)$ & $\ldots$ \\
\hline Unstable angina & 40.4 & 48.6 & $-8.1(-30.0,13.7)$ & $\ldots$ \\
\hline Lesion length, mm & $9.5 \pm 3.2$ & $8.8 \pm 2.8$ & $0.70(-0.64,2.04)$ & $\ldots$ \\
\hline Discrete $(<10 \mathrm{~mm})$ & 64.3 & 64.9 & $-0.6(-21.7,20.6)$ & $\ldots$ \\
\hline Tubular (10-20 mm) & 35.7 & 35.1 & $0.6(-20.6,21.7)$ & $\ldots$ \\
\hline \multicolumn{5}{|l|}{ Lesion type (AHA/ACC) } \\
\hline A & 9.5 & 2.7 & $6.8(-3.5,17.1)$ & $\ldots$ \\
\hline B1 & 28.6 & 32.4 & $-3.9(24.2,16.5)$ & $\ldots$ \\
\hline B2 & 61.9 & 64.9 & $-3.0(-24.2,18.3)$ & $\ldots$ \\
\hline C & 0 & 0 & 0 & $\ldots$ \\
\hline Mean stent diameter, mm & $2.8 \pm 0.2$ & $2.9 \pm 0.2$ & $-0.10(-0.22,0.01)$ & 0.08 \\
\hline 3.5 & 2.3 & 5.4 & $-3.0(-11.6,5.4)$ & 0.59 \\
\hline 3.0 & 58.1 & 73.0 & $-14.8(-35.3,5.7)$ & 0.24 \\
\hline 2.5 & 39.5 & 21.6 & $17.9(-1.8,37.6)$ & 0.10 \\
\hline Balloon-artery ratio & $1.3 \pm 0.1$ & $1.3 \pm 0.2$ & $0(-0.09,0.09)$ & 0.96 \\
\hline Maximal inflation pressure, atm & $14.2 \pm 3.5$ & $14.2 \pm 3.4$ & $-0.03(-1.5,1.5)$ & 0.97 \\
\hline Postprocedural dissection & & & & 1.00 \\
\hline None & 76.2 & 75.7 & $0.5(-18.4,19.4)$ & $\cdots$ \\
\hline Type A & 7.1 & 2.7 & $4.4(-4.9,13.8)$ & $\cdots$ \\
\hline Type B & 9.5 & 18.9 & $-9.4(-24.8,6.0)$ & $\cdots$ \\
\hline Type C & 7.1 & 2.7 & $4.4(-4.9,13.8)$ & $\ldots$ \\
\hline Other & 0 & 0 & 0 & $\cdots$ \\
\hline \multicolumn{5}{|l|}{ ॥ } \\
\hline $\mathrm{n}$ & 40 & 38 & $\ldots$ & $\ldots$ \\
\hline Age, y & $61 \pm 10$ & $59 \pm 11$ & $1.3(-3.5,6.2)$ & $\ldots$ \\
\hline Male sex & 72.5 & 81.6 & $-9.1(-27.6,9.5)$ & $\ldots$ \\
\hline Diabetes mellitus & 22.5 & 21.1 & $1.4(-16.9,19.8)$ & $\cdots$ \\
\hline Unstable angina & 51.2 & 54.0 & $-2.7(-25.2,19.6)$ & $\ldots$ \\
\hline Lesion length, mm & $9.0 \pm 2.9$ & $8.4 \pm 2.2$ & $0.54(-0.62,1.70)$ & $\cdots$ \\
\hline Discrete $(<10 \mathrm{~mm})$ & 89.5 & 83.8 & $5.7(-9.7,21.1)$ & $\ldots$ \\
\hline Tubular (10-20 mm) & 10.5 & 18.9 & $-8.7(-24.5,7.1)$ & \\
\hline \multicolumn{5}{|l|}{ Lesion type (AHA/ACC) } \\
\hline A & 5.1 & 5.4 & $-0.3(-10.3,9.8)$ & $\ldots$ \\
\hline B1 & 53.8 & 35.1 & $18.7(-3.2,40.7)$ & $\cdots$ \\
\hline B2 & 41.0 & 59.5 & $-18.4(-40.5,3.7)$ & $\ldots$ \\
\hline C & 0 & 0 & 0 & $\cdots$ \\
\hline Mean stent diameter, mm & $3.0 \pm 0.3$ & $3.1 \pm 0.2$ & $-0.03(-0.16,0.09)$ & 0.60 \\
\hline 3.5 & 26.1 & 26.3 & $-0.1(-19.4,19.1)$ & 1.00 \\
\hline 3.0 & 61.9 & 68.4 & $-6.5(-27.3,14.3)$ & 0.64 \\
\hline 2.5 & 11.9 & 5.2 & $-6.6(-5.4,18.7)$ & 0.44 \\
\hline Balloon-artery ratio & $1.1 \pm 0.1$ & $1.2 \pm 0.2$ & $-0.1(-0.1,-0.03)$ & 0.008 \\
\hline Maximal inflation pressure, atm & $14.7 \pm 3.1$ & $15.5 \pm 2.6$ & $-0.7(-2.0,0.5)$ & 0.26 \\
\hline Postprocedural dissection & & & & 0.62 \\
\hline None & 71.8 & 64.9 & $6.9(-14.0,27.8)$ & $\ldots$ \\
\hline Type A & 10.3 & 21.6 & $-11.4(-27.7,5.0)$ & $\ldots$ \\
\hline Type B & 7.7 & 8.1 & $-0.4(-12.6,11.7)$ & $\ldots$ \\
\hline Type C & 5.1 & 2.7 & $2.4(-6.2,11.1)$ & $\ldots$ \\
\hline
\end{tabular}

Downloaded from http://circ.ahajournals.org/ by guest on July 5, 2012 
TABLE 1. (Continued)

\begin{tabular}{|c|c|c|c|c|}
\hline Stratum/Parameter & SES & BS & Difference $(95 \% \mathrm{Cl})$ & $P$ \\
\hline Other & 5.1 & 0 & $5.1(-1.8,12.1)$ & ... \\
\hline \multicolumn{5}{|l|}{ III } \\
\hline$n$ & 38 & 42 & $\ldots$ & ... \\
\hline Age, y & $62 \pm 9$ & $57 \pm 9$ & $5.3(1.2,9.4)$ & $\ldots$ \\
\hline Male sex & 63.2 & 88.1 & $-24.9(43.1,-6.7)$ & ... \\
\hline Diabetes mellitus & 5.3 & 16.7 & $-11.4(-24.7,1.9)$ & $\ldots$ \\
\hline Unstable angina & 54.0 & 52.3 & $1.6(-20.3,23.7)$ & ... \\
\hline Lesion length, mm & $10.1 \pm 3.8$ & $11.4 \pm 3.4$ & $-1.27(-2.91,0.38)$ & ... \\
\hline Discrete $(<10 \mathrm{~mm})$ & 85.7 & 74.4 & $11.4(-6.6,29.3) \ldots$ & \\
\hline Tubular (10-20 mm) & 14.3 & 25.6 & $-11.4(-29.3,6.6)$ & ... \\
\hline \multicolumn{5}{|l|}{ Lesion type (AHA/ACC) } \\
\hline$A$ & 7.9 & 4.8 & $3.1(-7.6,13.9)$ & $\ldots$ \\
\hline B1 & 34.2 & 35.7 & $-1.5(-22.4,19.4)$ & $\ldots$ \\
\hline B2 & 57.9 & 59.5 & $-1.6(-23.2,20.0)$ & $\ldots$ \\
\hline C & 0 & 0 & 0 & ... \\
\hline Mean stent diameter, mm & $3.3 \pm 0.2$ & $3.2 \pm 0.2$ & $0.07(-0.04,0.18)$ & 0.22 \\
\hline 3.5 & 64.9 & 51.2 & $13.7(-7.7,35.1)$ & 0.26 \\
\hline 3.0 & 35.1 & 48.8 & $-13.7(-35.1,7.7)$ & 0.26 \\
\hline 2.5 & 0 & 0 & 0 & $\ldots$ \\
\hline Balloon-artery ratio & $1.0 \pm 0.1$ & $1.0 \pm 0.1$ & $0.03(-0.05,0.10)$ & 0.51 \\
\hline Maximal inflation pressure, atm & $16.2 \pm 3.6$ & $15.1 \pm 3.2$ & $1.0(-0.4,2.5)$ & 0.18 \\
\hline Postprocedural dissection & & & & 0.76 \\
\hline None & 86.8 & 83.3 & $3.5(-12.1,19.1)$ & $\ldots$ \\
\hline Type A & 0 & 7.1 & $-7.1(-14.9,0.6)$ & $\ldots$ \\
\hline Type B & 7.9 & 9.5 & $-1.6(-14.0,, 10.7)$ & $\ldots$ \\
\hline Type C & 5.3 & 0 & $5.3(-1.8,12.4)$ & $\ldots$ \\
\hline Other & 0 & 0 & 0 & $\ldots$ \\
\hline
\end{tabular}

\section{Discussion}

We investigated the relationship between vessel diameter and angiographic outcome 6 months after sirolimus-eluting stent implantation in patients in the RAVEL trial. The main findings of the study are that sirolimus-eluting stents prevent restenosis irrespective of vessel diameter and do not show the classic inverse relationship of vessel diameter to restenosis rate.

Quantitative coronary angiography convincingly demonstrates the absence of neointimal proliferation and restenosis in all patients treated with the sirolimus-eluting stent within the first 6 months, unlike those treated with bare metal stents. This truly remarkable finding creates a totally new paradigm in interventional cardiology and puts paid to the wellestablished existing paradigm, the classic inverse relationship between vessel diameter and restenosis rate. ${ }^{3}$

\section{Prevention of Neointima Growth}

Neointimal growth is a normal reaction to vascular injury. Smooth muscle cells are considered to be the main components of coronary artery neointima after stent implantation, and the severity of the reaction may be modulated by the extent of stent-induced vessel injury ${ }^{14}$ and the inflammatory reaction around the stent struts. ${ }^{15}$
Vessel injury is influenced by stent surface material, geometric configuration, implantation technique, and vessel size. ${ }^{16}$ Neointimal hyperplasia and persistent tissue proliferation are related to the degree of vessel injury (balloon/artery ratio $\times$ inflation pressure). ${ }^{17}$

In our patients, 2 stent configurations (6-cell and 7-cell designs) were used. Stent implantation technique varied with vessel size. In small vessels, a relatively higher balloon to artery ratio of 1.3 was achieved, whereas the balloon to artery ratio was lower (1.0) in large vessels. Conversely, the inflation pressure was lower in small vessels than in larger vessels (14 atm versus $16 \mathrm{~atm}$ ).

In the present study, the effectiveness of the sirolimuseluting stent was extremely strong and was affected neither by established risk factors for restenosis nor by stent configuration, balloon to artery ratio, or balloon pressure. Other than treatment allocation, the only independent predictor for late loss was the postprocedural MLD.

The very low late loss, which is consistently reported in all studies with sirolimus-eluting stents, ${ }^{8-10}$ raised concerns about late lumen enlargement. In the present study, there was evidence of late lumen gain (negative late lumen loss) in 3\% of SES patients. 
TABLE 2. Quantitative Coronary Angiography Analysis of Sirolimus-Eluting Stents and Bare Stents, Stratified by Vessel Size

\begin{tabular}{|c|c|c|c|c|c|c|c|c|}
\hline \multirow[b]{3}{*}{ Stratum/Parameter } & \multirow{2}{*}{\multicolumn{2}{|c|}{ Vessel Segment }} & \multirow{2}{*}{\multicolumn{2}{|c|}{ Stent Segment }} & \multicolumn{4}{|c|}{ Target Lesion } \\
\hline & & & & & \multicolumn{2}{|c|}{ Proximal Edge } & \multicolumn{2}{|c|}{ Distal Edge } \\
\hline & SES & BS & SES & BS & SES & BS & SES & BS \\
\hline \multicolumn{9}{|l|}{ I } \\
\hline \multicolumn{9}{|l|}{$\mathrm{RD}, \mathrm{mm}$} \\
\hline Before & $2.09 \pm 0.21$ & $2.07 \pm 0.21$ & $\ldots$ & $\ldots$ & $\ldots$ & $\ldots$ & $\ldots$ & $\ldots$ \\
\hline After & $2.30 \pm 0.30$ & $2.26 \pm 0.33$ & $2.38 \pm 0.26$ & $2.40 \pm 0.31$ & $\ldots$ & $\ldots$ & $\ldots$ & $\ldots$ \\
\hline Follow-up & $2.34 \pm 0.42$ & $2.11 \pm 0.33$ & $2.45 \pm 0.38$ & $2.12 \pm 0.32$ & $\ldots$ & $\ldots$ & $\ldots$ & $\ldots$ \\
\hline \multicolumn{9}{|l|}{ MLD, mm } \\
\hline Before & $0.82 \pm 0.19$ & $0 . .77 \pm 0.18$ & $0.82 \pm 0.19$ & $0.77 \pm 0.18$ & $1.84 \pm 0.38$ & $1.71 \pm 0.40$ & $1.53 \pm 0.31$ & $1.56 \pm 0.36$ \\
\hline After & $1.66 \pm 0.30$ & $1.57 \pm 0.30$ & $2.05 \pm 0.25$ & $2.06 \pm 0.29$ & $2.01 \pm 0.37$ & $1.95 \pm 0.33$ & $1.82 \pm 0.31$ & $1.71 \pm 0.33$ \\
\hline Follow-up & $1.69 \pm 0.38$ & $1.20 \pm 0.37$ & $2.04 \pm 0.32$ & $1.26 \pm 0.41$ & $1.96 \pm 0.42$ & $1.73 \pm 0.43$ & $1.85 \pm 0.35$ & $1.69 \pm 0.41$ \\
\hline $\mathrm{RR}, \%$ & 0 & 35 & $\ldots$ & $\ldots$ & $\ldots$ & $\ldots$ & $\ldots$ & $\ldots$ \\
\hline $\mathrm{LL}, \mathrm{mm}$ & $-0.04 \pm 0.29$ & $0.37 \pm 0.37$ & $0.01 \pm 0.25$ & $0.80 \pm 0.43$ & $0.04 \pm 0.34$ & $0.20 \pm 0.46$ & $-0.05 \pm 0.29$ & $0.03 \pm 0.45$ \\
\hline \multicolumn{9}{|l|}{ ॥ } \\
\hline \multicolumn{9}{|l|}{$\mathrm{RD}, \mathrm{mm}$} \\
\hline Before & $2.58 \pm 0.14$ & $2.60 \pm 0.14$ & $\ldots$ & $\ldots$ & $\ldots$ & $\ldots$ & $\ldots$ & $\ldots$ \\
\hline After & $2.60 \pm 0.27$ & $2.71 \pm 0.34$ & $2.74 \pm 0.21$ & $2.81 \pm 0.25$ & $\ldots$ & $\ldots$ & $\ldots$ & $\ldots$ \\
\hline Follow-up & $2.77 \pm 0.47$ & $2.62 \pm 0.31$ & $2.84 \pm 0.42$ & $2.58 \pm 0.24$ & $\ldots$ & $\ldots$ & $\ldots$ & $\ldots$ \\
\hline \multicolumn{9}{|l|}{ MLD, mm } \\
\hline Before & $0.97 \pm 0.26$ & $0.94 \pm 0.21$ & $0.97 \pm 0.26$ & $0.94 \pm 0.21$ & $2.29 \pm 0.44$ & $2.19 \pm 0.50$ & $2.00 \pm 0.38$ & $2.08 \pm 0.40$ \\
\hline After & $1.99 \pm 0.26$ & $2.06 \pm 0.32$ & $2.45 \pm 0.27$ & $2.41 \pm 0.25$ & $2.45 \pm 0.31$ & $2.48 \pm 0.33$ & $2.09 \pm 0.31$ & $2.22 \pm 0.36$ \\
\hline Follow-up & $2.06 \pm 0.43$ & $1.58 \pm 0.50$ & $2.44 \pm 0.39$ & $1.59 \pm 0.53$ & $2.38 \pm 0.47$ & $2.13 \pm 0.45$ & $2.23 \pm 0.45$ & $2.13 \pm 0.32$ \\
\hline $\mathrm{RR}, \%$ & 0 & 26 & $\ldots$ & $\ldots$ & $\ldots$ & $\ldots$ & $\ldots$ & $\ldots$ \\
\hline $\mathrm{LL}, \mathrm{mm}$ & $-0.07 \pm 0.35$ & $0.56 \pm 0.51$ & $0.01 \pm 0.38$ & $0.88 \pm 0.57$ & $0.08 \pm 0.42$ & $0.40 \pm 0.39$ & $-0.14 \pm 0.31$ & $0.14 \pm 0.41$ \\
\hline \multicolumn{9}{|l|}{ III } \\
\hline \multicolumn{9}{|l|}{$\mathrm{RD}, \mathrm{mm}$} \\
\hline Before & $3.25 \pm 0.38$ & $3.22 \pm 0.30$ & $\ldots$ & $\ldots$ & $\ldots$ & $\ldots$ & $\ldots$ & $\ldots$ \\
\hline After & $2.99 \pm 0.43$ & $3.01 \pm 0.33$ & $3.18 \pm 0.34$ & $3.19 \pm 0.29$ & $\ldots$ & $\ldots$ & $\ldots$ & $\ldots$ \\
\hline Follow-up & $3.09 \pm 0.45$ & $2.91 \pm 0.50$ & $3.29 \pm 0.32$ & $2.97 \pm 0.49$ & $\ldots$ & $\ldots$ & $\ldots$ & $\ldots$ \\
\hline \multicolumn{9}{|l|}{ MLD, mm } \\
\hline Before & $1.04 \pm 0.41$ & $1.13 \pm 0.47$ & $1.04 \pm 0.41$ & $1.13 \pm 0.47$ & $2.75 \pm 0.59$ & $2.75 \pm 0.59$ & $2.47 \pm 0.46$ & $2.55 \pm 0.50$ \\
\hline After & $2.31 \pm 0.36$ & $2.35 \pm 0.27$ & $2.81 \pm 0.28$ & $2.73 \pm 0.31$ & $2.98 \pm 0.38$ & $2.89 \pm 0.45$ & $2.51 \pm 0.50$ & $2.65 \pm 0.32$ \\
\hline Follow & $2.35 \pm 0.33$ & $1.89 \pm 0.46$ & $2.86 \pm 0.37$ & $2.01 \pm 0.56$ & $2.96 \pm 0.32$ & $2.64 \pm 0.62$ & $2.60 \pm 0.45$ & $2.47 \pm 0.43$ \\
\hline $\mathrm{RR}, \%$ & 0 & 20 & $\ldots$ & $\ldots$ & $\ldots$ & $\ldots$ & $\ldots$ & $\ldots$ \\
\hline $\mathrm{LL}, \mathrm{mm}$ & $-0.06 \pm 0.25$ & $0.47 \pm 0.50$ & $-0.06 \pm 0.35$ & $0.74 \pm 0.57$ & $0.03 \pm 0.43$ & $0.27 \pm 0.56$ & $-0.09 \pm 0.31$ & $0.18 \pm 0.43$ \\
\hline
\end{tabular}

$\mathrm{RR}$ values are given as percentages; all other values are mean $\pm \mathrm{SD}$ in millimeters.

$\mathrm{RR}$ indicates restenosis rate; and LL, late lumen loss.

Furthermore, minimal but consistently negative late loss was seen at the distal edges of the stent. This phenomenon might be related to the downstream elution of the drug.

Although the finding of late lumen gain in a very small percentage of patients is interesting, it is worth noting that there have been no clinical events attributable to this phenomenon in the patients treated with the sirolimus-eluting stent at 1-year follow-up, or in the patients of Sousa et al ${ }^{10}$ for up to 2 years. Mechanistic angiographic analysis of the Sao Paulo series ${ }^{10}$ showed stable lumen dimensions with minimal late lumen loss between 4- and 12-month follow-up (in-stent MLD $2.90 \pm 05 \mathrm{~mm}$ at 4 months and $2.87 \pm 0.4 \mathrm{~mm}$ at 12 month; slow-release group) that matches well with the stable clinical result.

\section{The Importance of Late Loss as a Predictor of Restenosis}

The classic inverse relationship between vessel diameter and restenosis rate was not seen in the sirolimus-eluting stent group. This offers new therapeutic options for small vessels, in which conventional stenting is of questionable value. ${ }^{5}$ This is especially true for diabetic patients, who often have small arteries because of diffuse coronary artery disease. ${ }^{18}$ In addition, they frequently have an exaggerated neointimal 
TABLE 3. Univariate Predictors of Late Loss for All Patients Treated

\begin{tabular}{|c|c|c|c|c|}
\hline Univariate Predictor of Late Loss & Parameter & Standard Error & R2 & $P$ \\
\hline Treatment & 0.814371 & 0.059535 & 0.4653 & $<0.001^{*}$ \\
\hline MLD after procedure, mm & 0.223776 & 0.100029 & 0.0227 & $0.026^{*}$ \\
\hline Age, y & -0.00724 & 0.003924 & 0.0156 & 0.066 \\
\hline Total length of stents, mm & 0.021843 & 0.012981 & 0.0130 & 0.094 \\
\hline Eccentric IB lesion before procedure & -0.13079 & 0.087642 & 0.0106 & 0.137 \\
\hline Smoking, previous or current & -0.12488 & 0.088079 & 0.0093 & 0.158 \\
\hline Diabetes mellitus & 0.144408 & 0.103526 & 0.0090 & 0.165 \\
\hline Number of stents & 0.222425 & 0.168080 & 0.0081 & 0.187 \\
\hline Thrombus lesion before procedure & -0.28244 & 0.230559 & 0.0072 & 0.222 \\
\hline MLD before procedure, $\mathrm{mm}$ & 0.148352 & 0.121476 & 0.0069 & 0.223 \\
\hline Diameter stenosis after procedure, \% & -0.03379 & 0.003864 & 0.0045 & 0.328 \\
\hline Lesion type B2 & 0.075694 & 0.082215 & 0.0039 & 0.358 \\
\hline Diameter stenosis after procedure, $\%$ & -0.00591 & 0.006459 & 0.0039 & 0.361 \\
\hline QCA lesion length before procedure, $\mathrm{mm}$ & 0.011469 & 0.012559 & 0.0040 & 0.362 \\
\hline Unstable angina at screening & 0.072019 & 0.082139 & 0.0036 & 0.382 \\
\hline Male sex & 0.080158 & 0.096519 & 0.0032 & 0.407 \\
\hline Hypertension & 0.064092 & 0.081323 & 0.0029 & 0.432 \\
\hline Eccentric $1 \mathrm{~A}$ lesion before procedure & 0.064127 & 0.084667 & 0.0028 & 0.450 \\
\hline Eccentric lla lesion before procedure & 0.102716 & 0.138269 & 0.0026 & 0.458 \\
\hline Previous PTCA & -0.07700 & 0.108119 & 0.0024 & 0.477 \\
\hline Previous CABG & -0.20522 & 0.348366 & 0.0016 & 0.556 \\
\hline Hypercholesterolemia & -0.04599 & 0.081463 & 0.0015 & 0.573 \\
\hline Eccentric IIB lesion before procedure & 0.090999 & 0.186324 & 0.0011 & 0.626 \\
\hline LAD treated & -0.03735 & 0.081421 & 0.0010 & 0.647 \\
\hline Readily accessible lesion before procedure & 0.052347 & 0.132952 & 0.0007 & 0.694 \\
\hline Previous myocardial infarction & 0.020693 & 0.084594 & 0.0003 & 0.807 \\
\hline $\begin{array}{l}\text { Calcification (moderate/heavy) before } \\
\text { procedure }\end{array}$ & -0.01526 & 0.096575 & 0.0001 & 0.875 \\
\hline Reference diameter before procedure, $\mathrm{mm}$ & 0.003010 & 0.076780 & 0.0000 & 0.969 \\
\hline
\end{tabular}

proliferative response that manifests as significantly greater late loss at the treatment site and a resultant 2-fold increase in in-stent restenosis in small vessels (44\% versus $23 \%$, $P=0.002)$ as compared with nondiabetic patients with similar-sized vessels. ${ }^{19}$ In our study, diabetes mellitus did not attenuate the effectiveness of the sirolimus-eluting stent. These findings contrast markedly with what was seen in the bare stent group. Restenosis rates almost doubled from the tertile with the largest diameter vessels to the one with the

TABLE 4. Multivariate Predictors of Late Loss

\begin{tabular}{lcccc}
\hline $\begin{array}{l}\text { Multivariate Predictor of } \\
\text { Late Loss }\end{array}$ & Parameter & Standard Error & R2 & $P$ \\
\hline Treatment & 0.810123 & 0.058706 & 0.4653 & $0.0001^{*}$ \\
MLD after procedure, mm & 0.196763 & 0.072959 & 0.4829 & $0.0076^{\star}$ \\
\hline
\end{tabular}

Predictors were chosen by stepwise linear regression using an entry criterion of 0.20 and a stay criterion of 0.05 .

*Significant $P$ value. smallest vessels (20\% to $35 \%)$, whereas late loss increased only modestly $(0.74 \mathrm{~mm}$ to $0.80 \mathrm{~mm})$. This dramatic increase in restenosis rate is explicable on the basis of hydraulics. A late loss of $0.80 \mathrm{~mm}$ in a $3.0-\mathrm{mm}$ diameter vessel versus a $2.0-\mathrm{mm}$ diameter vessel results in a $46 \%$ versus a $64 \%$ obstruction. Late loss is the most sensitive and operatorindependent assessment of the effect of drug-eluting stents and can be used to predict what the restenosis rate will be in vessels of different diameters. Simply reporting angiographic restenosis rates, which can be influenced by case selection and operator techniques, is no longer sufficient in the era of drug-eluting stents.

\section{Conclusion}

Sirolimus-eluting stents prevent neointimal proliferation and late lumen loss irrespective of the vessel size. The classic inverse relationship between vessel diameter and restenosis rate was seen in the bare stent group but not in the sirolimus- 
eluting stent group. This finding with the sirolimus-eluting stent has the potential to considerably expand the use of these stents in smaller vessels and to eliminate the present difference in reintervention rates between patients treated with coronary artery bypass surgery and stenting. ${ }^{20}$

\section{Acknowledgments}

Dr Regar is supported by a grant of the Deutsche Forschungsgemeinschaft. We thank Dr B. Firth for his critical review of the manuscript.

\section{References}

1. Popma JJ, Hunninghake DB, Arad Y, et al. Roundtable discussion: therapeutic challenges and deficiencies. Am J Cardiol. 2001;88: $42 \mathrm{~K}-43 \mathrm{~K}$

2. Schwartz RS, Topol EJ, Serruys PW, et al. Artery size, neointima, and remodeling: time for some standards. J Am Coll Cardiol. 1998;32: 2087-2094.

3. Foley DP, Melkert R, Serruys PW. Influence of coronary vessel size on renarrowing process and late angiographic outcome after successful balloon angioplasty. Circulation. 1994;90:1239-1251.

4. Kuntz RE, Gibson CM, Nobuyoshi M, et al. Generalized model of restenosis after conventional balloon angioplasty, stenting and directional atherectomy. J Am Coll Cardiol. 1993;21:15-25.

5. Doucet S, Schalij MJ, Vrolix MC, et al. Stent placement to prevent restenosis after angioplasty in small coronary arteries. Circulation. 2001; 104:2029-2033.

6. Kastrati A, Schomig A, Dirschinger J, et al. A randomized trial comparing stenting with balloon angioplasty in small vessels in patients with symptomatic coronary artery disease. ISAR- SMART Study Investigators. Intracoronary Stenting or Angioplasty for Restenosis Reduction in Small Arteries. Circulation. 2000;102:2593-2598.

7. Marx SO, Marks AR. Bench to bedside: the development of rapamycin and its application to stent restenosis. Circulation. 2001;104:852-855.

8. Sousa JE, Costa MA, Abizaid A, et al. Lack of neointimal proliferation after implantation of sirolimus-coated stents in human coronary arteries: a quantitative coronary angiography and three-dimensional intravascular ultrasound study. Circulation. 2001;103:192-195.
9. Rensing BJ, Vos J, Smits PC, et al. Coronary restenosis elimination with a sirolimus eluting stent: first European human experience with six month angiographic and intravascular ultrasonic follow-up. Eur Heart J. 2001; 22:2125-2130.

10. Sousa JE, Costa MA, Abizaid AC, et al. Sustained suppression of neointimal proliferation by sirolimus-eluting stents: one-year angiographic and intravascular ultrasound follow-up. Circulation. 2001;104: 2007-2011.

11. Morice MC, Serruys PW, Sousa JE, et al. A randomized comparison of a sirolimus-eluting stent with a standard stent for a coronary revascularization. N Engl J Med. 2002;346:1773-1780.

12. Reiber JH, Serruys PW, Kooijman CJ, et al. Assessment of short-, medium-, and long-term variations in arterial dimensions from computerassisted quantitation of coronary cineangiograms. Circulation. 1985;71: $280-288$.

13. Serruys PW, Luijten HE, Beatt KJ, et al. Incidence of restenosis after successful coronary angioplasty: a time- related phenomenon: a quantitative angiographic study in 342 consecutive patients at 1, 2, 3, and 4 months. Circulation. 1988;77:361-371.

14. Schwartz RS, Huber KC, Murphy JG, et al. Restenosis and the proportional neointimal response to coronary artery injury: results in a porcine model. J Am Coll Cardiol. 1992;19:267-274.

15. Kornowski R, Hong MK, Tio FO, et al. In-stent restenosis: contributions of inflammatory responses and arterial injury to neointimal hyperplasia. J Am Coll Cardiol. 1998;31:224-230.

16. Rogers C, Edelman ER. Endovascular stent design dictates experimental restenosis and thrombosis. Circulation. 1995;91:2995-3001.

17. Hoffmann R, Mintz GS, Mehran R, et al. Tissue proliferation within and surrounding Palmaz-Schatz stents is dependent on the aggressiveness of stent implantation technique. Am J Cardiol. 1999;83:1170-1174.

18. Saucedo JF, Popma JJ, Kennard ED, et al. Relation of coronary artery size to one-year clinical events after new device angioplasty of native coronary arteries (a New Approach to Coronary Intervention [NACI] Registry Report). Am J Cardiol. 2000;85:166-171.

19. Suselbeck T, Latsch A, Siri H, et al. Role of vessel size as a predictor for the occurrence of in-stent restenosis in patients with diabetes mellitus. Am J Cardiol. 2001;88:243-247.

20. Serruys PW, Unger F, Sousa JE, et al. Comparison of coronary-artery bypass surgery and stenting for the treatment of multivessel disease. N Engl J Med. 2001;344:1117-1124. 